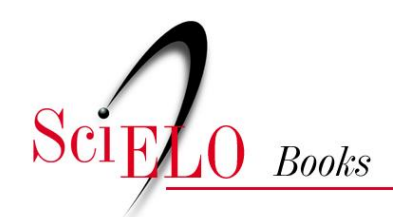

\title{
A abordagem etnográfica na investigação científica
}

\author{
Carmem Lúcia Guimarães de Mattos
}

\section{SciELO Books / SciELO Livros / SciELO Libros}

MATTOS, CLG. A abordagem etnográfica na investigação científica. In MATTOS, CLG., and CASTRO, PA., orgs. Etnografia e educação: conceitos e usos [online]. Campina Grande: EDUEPB, 2011. pp. 49-83. ISBN 978-85-7879-190-2. Available from SciELO Books < http://books.scielo.org>.

\section{(c) (1) @(2)}

All the contents of this work, except where otherwise noted, is licensed under a Creative Commons Attribution-Non Commercial-ShareAlike 3.0 Unported.

Todo o conteúdo deste trabalho, exceto quando houver ressalva, é publicado sob a licença Creative Commons Atribuição Uso Não Comercial - Partilha nos Mesmos Termos 3.0 Não adaptada.

Todo el contenido de esta obra, excepto donde se indique lo contrario, está bajo licencia de la licencia Creative Commons Reconocimento-NoComercial-CompartirIgual 3.0 Unported. 


\title{
A abordagem etnográfica na investigação científica ${ }^{1}$
}

\author{
Carmen Lúcia Guimarães de Mattos
}

Este capítulo explora a etnografia como uma abordagem de investigação científica para demonstrar como esta abordagem de pesquisa traz algumas contribuições importantes ao campo das pesquisas qualitativas, especialmente aquelas que se interessam pelos estudos das desigualdades sociais e dos processos de exclusão.

Introduz o conceito de etnografia e desenvolve aspectos que envolvem o trabalho etnográfico, informando que fazer etnografia implica em: 1) preocupar-se com uma análise holística ou dialética da cultura: 2) introduzir os atores sociais com uma participação ativa e dinâmica e modificadora das estruturas sociais; 3) preocupar-se em revelar as relações e interações significativas de modo a desenvolver a reflexividade sobre a ação de pesquisar, tanto pelo pesquisador quanto pelo pesquisado.

Sinaliza alguns cuidados que podem auxiliar o pesquisador a desenvolver este tipo de pesquisa, em particular preocupações com o período despendido no campo de investigação, a descrição densa e minuciosa dos dados coletados, o processo indutivo de análise, a questão da ética na pesquisa, dentre outros.

1 Texto apresentado originariamente no Curso de Etnografia ministrado pela autora na Faculdade de Educação da Universidade Federal Fluminense em 1990. Foi então publicado parcialmente em 2001 na Revista Espaço INES e posteriormente na Revista Sementes. 
O objetivo deste capítulo é informar pesquisadores que iniciam-se na proposta etnográfica com informações e conteúdos teóricos básicos que considera-se importante para situar este que pretendem utilizar a abordagem para o desenvolvimento de trabalhos científicos em especial na área das ciências humanas e sociais.

\section{Aspectos epistemológicos e conceituais}

A etnografia é um processo guiado preponderantemente pelo senso questionador do etnógrafo. Deste modo, a utilização de técnicas e procedimentos etnográficos, não segue padrões rígidos ou pré-determinados, mas sim, o senso que o etnógrafo desenvolve a partir do trabalho de campo no contexto social da pesquisa. Os instrumentos de coleta e análise utilizados nesta abordagem de pesquisa, muitas vezes, têm que ser formuladas ou recriadas para atender à realidade do trabalho de campo. Assim, na maioria das vezes, o processo de pesquisa etnográfica será determinado explícita ou implicitamente pelas questões propostas pelo pesquisador.

A etnografia como abordagem de investigação científica traz algumas contribuições para o campo das pesquisas qualitativas, em particular para os estudo que se interessam pelas desigualdades sociais, processos de exclusão e situações sóciointeracionais, por alguns motivos entre eles estão: Primeiro, preocupa-se com uma análise holística ou dialética da cultura, isto é, a cultura não é vista como um mero reflexo de forças estruturais da sociedade, mas como um sistema de significados mediadores entre as estruturas sociais e as ações e interações humanas.

Segundo, por introduzir os atores sociais com uma participação ativa e dinâmica no processo modificador das estruturas sociais. Neste sentido, Mehan (1992) afirma que o objeto de pesquisa pode ser o sujeito, sendo considerado como a agência humana no ato de significar as contradições sociais evidenciadas nestas estruturas e processos interacionais. 
Terceiro, por revelar as relações e interações ocorridas no interior das escolas, assim como de outras instituições parte dessas estruturas sociais de forma que esta se abra e evidencie os processos por elas engendrados e de difícil visibilidade para os sujeitos que dela fazem parte (ERICKSON, 1986). Neste sentido, o sujeito da pesquisa, historicamente ator das ações sociais e interacionais, contribui para significar o universo pesquisado exigindo a constante reflexão e reestruturação do processo de questionamento do pesquisador.

Etnografia é também conhecida como: observação participante, pesquisa interpretativa, pesquisa hermenêutica, dentre outras. Compreende o estudo, pela observação direta e por um período de tempo, das formas costumeiras de viver de um grupo particular de pessoas: um grupo de pessoas associadas de alguma maneira, uma unidade social representativa para estudo, seja ela formada por poucos ou muitos elementos, por exemplo: uma escola toda ou um grupo de estudo em uma determinada sala de aula.

A etnografia estuda preponderantemente os padrões mais previsíveis das percepções e comportamento manifestos em sua rotina diária dos sujeitos estudados. Estuda ainda os fatos e eventos menos previsíveis ou manifestados particularmente em determinado contexto interativo entre as pessoas ou grupos.

Em etnografia, holisticamente, observa-se os modos como esses grupos sociais ou pessoas conduzem suas vidas com o objetivo de revelar o significado cotidiano, nos quais as pessoas agem. O objetivo é documentar, monitorar, encontrar o significado da ação.

Tanto a etnografia mais tradicional (GEERTZ, 1989; LÉVISTRAUSS, 1988) quanto a mais moderna (ERIKSON, 1992; WOODS, 1986; MEHAN, 1992; WILLIS, 1977), envolvem longos períodos de observação, um a dois anos, preferencialmente. Este período se faz necessário para que o pesquisador possa entender e validar o significado das ações dos participantes, de forma que este seja o mais representativo possível do significado que as próprias pessoas pesquisadas dariam a mesma ação, evento ou situação interpretada. 
Um dos marcos teóricos que mais se destaca nos estudos etnográficos é o interacionismo simbólico (SCHÜTZ, 1962; PARK; BURGESS, 1921; BLUMER, 1937; THOMAS, 1927), especialmente, aplicados às análises do processo de socialização. Nesta teoria esse processo é entendido como uma negociação constante que não se limita ao vínculo social.

O interacionismo simbólico sintetiza uma das principais escolas de pensamento da sociologia e tem como uma de suas características incorporar a reflexividade na análise da ação (MEAD, 1938). Dentro deste enquadre teórico, buscamos no trabalho de Erickson $(1986,1984)$, dados para explicar o significado da etnografia aplicada à sala de aula e a história intelectual da etnografia, sinalizando o tipo de questões que devemos ter em mente quando usamos esta abordagem de pesquisa.

\section{Etnografia \& Etnologia}

Para entender a abordagem etnográfica na investigação científica se faz necessário distinguir a etnografia de etnologia. Um dos pontos que une essas duas abordagens de pesquisa é o interesse comparativo e a conexão histórica que possuem.

A Etnologia é um termo originário do século XIX para designar estudos comparativos dos modos de vida dos seres humanos. Neste período da história muitos estudos voltaramse para a origem da vida humana: por exemplo, a arqueologia, a linguística histórica, desenvolveu-se na tentativa de revelar a origem da linguagem, a origem do homem.

A Etnologia se origina da composição das palavras etno do grego etnoe, que designa os outros povos que não eram gregos (persas, latinos, egípcios) e da palavra. A palavra grega elenoe designava o povo grego e etnoe todos os outros povos. A parte $\log (0)$ da palavra, significa saber sobre, estudo científico sobre. Portanto, etnologia é o termo para o estudo sistemático ou científico sobre o outro. $\mathrm{O}$ estudo comparativo sistemático da variedade de outros povos diferente do nosso. Etnologia é ramo da antropologia cultural que estuda a cultura dos povos naturais, é o estudo e o conhecimento, sob o aspecto cultural, das populações primitivas. 
A Etnologia emerge como ciência neste contexto, juntamente com a arqueologia, filologia, linguística histórica, paleontologia e a teoria geral da evolução em biologia. Uma das grandes questões do início do século XIX foi o desenvolvimento histórico. Ao mesmo tempo em que a questão da diversidade desse desenvolvimento também emerge neste contexto ainda no mesmo período, os europeus ocidentais estavam engajados no colonialismo em todo o mundo, descobrindo uma variedade imensa de sociedades desconhecidas e radicalmente diferentes nas formas básicas de organização de grupamentos humanos, religião, linguagem. Interesses em estudos comparativos emergiram deste contexto. Portanto, a etnologia apareceu primeiramente em estudos antropológicos ingleses, 50 ou 60 anos antes do aparecimento da etnografia.

A etnografia desenvolve-se no final do século XIX e início do século XX, como uma tentativa de observação mais holística dos modos de vida das pessoas. Foi encontrada primeiramente em livros de viagem, descrevendo sociedades exóticas. Muitos desses livros foram criticados por serem incompletos ou por dramatizarem excessivamente os fatos descritos. Houve também neste período um estudo de caso descrevendo os modos de vida desses povos exóticos, introduzindo desta forma a etnografia que daí se desenvolveu. Um dos marcos históricos na etnografia é o trabalho de Margaret Mead (1928), um trabalho monográfico em pesquisa educacional desenvolvido na universidade de Columbia que tem sido um marco na etnografia até a atualidade. No entanto, a etnologia ficou e ainda permanece como suporte para a etnografia moderna.

Etnografia - Grafia vem do grego graf(o) significa escrever sobre, escrever sobre um tipo particular - um etn(o) ou uma sociedade em particular. Antes de investigadores iniciarem estudos mais sistemáticos sobre uma determinada sociedade ele escreviam todos os tipos de informações sobre os outros povos por eles desconhecidos. Etnografia é a especialidade da antropologia, que tem por fim o estudo e a descrição dos povos, sua língua, raça, religião, e manifestações materiais de suas atividades, é parte ou disciplina integrante da etnologia é a forma de descrição da cultura material de um determinado povo. 
Para Geertz, praticar etnografia não é somente estabelecer relações, selecionar informantes transcrever textos, levantar genealogias, mapear campos, manter um diário " o que define é o tipo de esforço intelectual que ele representa: um risco elaborado para uma "descrição densa" (GEERTZ, 1989, p. 15).

A maior preocupação da etnografia é obter uma descrição densa, a mais completa possível, sobre o que um grupo particular de pessoas faz e o significado das perspectivas imediatas que eles têm do que eles fazem; esta descrição é sempre escrita com a comparação etnológica em mente. O objeto da etnografia é esse conjunto de significantes em termos dos quais os eventos, fatos, ações, e contextos, são produzidos, percebidos e interpretados, e sem os quais não existem como categoria cultural. Esses conjuntos de significantes nos apresentam como estruturas inter-relacionadas, em múltiplos níveis (OGBU, 1981) de interpretação.

Etnografia é a escrita do visível. A descrição etnográfica depende das qualidades de observação, de sensibilidade ao outro, do conhecimento sobre o contexto estudado, da inteligência e da imaginação científica do etnógrafo.

Tradicionalmente, os homens fazem comparações entre sua própria cultura e as de outros povos. Como também, pessoas hierarquicamente mais afluentes observam e comparam as pessoas de menos afluência, sempre observando o outro como diferente de si mesmo. Neste sentido, o que sempre existiu foi uma comparação entre os modos de vida de outros povos que eu estou descrevendo e o meu próprio. Existiu também uma comparação no sentido mais amplo, uma ideia de que o modo de viver comunitário é representativo de um conjunto de opções, por modos de organizações que eram muito mais variados do que as opções oferecidas. Por analogia, este é o modo como pensamos a linguagem como representativa de uma certa escolha na forma de organização social, o que é muito parecido com o que fazemos hoje como etnógrafos. A etnografia sempre teve interesse na comparação etnológica e a maioria das pessoas que faz este trabalho hoje continua a utilizar este instrumento de análise. $\mathrm{O}$ interesse comparativo na 
etnografia é aliado ao interesse na descrição holística da cena, do evento social, e/ou da interação grupal que nos propomos investigar. Ao estudarmos uma sociedade tentamos estudar 0 todo desta sociedade. Ao estudarmos uma vila, observaremos a vila toda - jovens, velhos, área urbana, rural, relações intergeracionais, relações de gênero, de classe - os fatos sociais que ocorrem neste contexto.

Na moderna etnografia, o legado da etnologia é o interesse no desenvolvimento como um todo, dentro de uma dada sociedade, e o interesse em todos os tipos de variações deste desenvolvimento. Uma distinção entre a etnologia e etnografia existe particularmente em estudos de casos comparativos. Em etnografia existe o interesse da sociedade local ou grupo estudado em descobrir e relatar o mais detalhadamente possível todos os tipos de variações que ocorrem dentro deste grupo. Nós não estamos interessados numa forma única de variação em relação ao total da variação humana, mas estamos também interessados em exaustivamente analisar qualquer forma de variação existente no grupo local. Se numa comunidade local existe mais de uma maneira de organização social do grupo, por exemplo, em relação à linguagem, classe social e gênero, nós sempre vamos querer descobrir todos os modos de agrupamento daquele grupo em particular.

\section{Microanálise etnográfica}

A microanálise etnográfica é um instrumento da etnografia, frequentemente utilizada nos estudos da linguagem é caracterizada como: sociolinguística da comunicação, microanálise sociolinguística, sociolinguística interacional, análise de contexto, análise de discurso, análise da conversação. Considerada como micro porque estuda-se particularmente um evento ou parte dele, ao mesmo tempo em que se dá ênfase ao estudo das relações sociais em grupo como um todo, holisticamente (LUTZ,1983). Em microanálise ao mesmo tempo em que se dá ênfase ao significado das formas de envolvimento das pessoas como atores, exige-se do pesquisador um detalhamento criterioso na descrição do comportamento através da transcrição 
linguística verbal e não-verbal de comportamento - olhares, pausas, tom de voz, detalhes da interação e o que isto significa (ERICKSON, 1982, 1992; KENDON, 1977). Na microanálise etnográfica existe uma preocupação com o interesse dos atores sociais na escolha de uma determinada forma de comportamento e qual o significado desta escolha. Portanto, enfatizar-se o significado da interação como um todo, a relação entre a cena imediata da interação social de um grupo e o significado do fato social ocorrido em grandes contextos culturais, por exemplo: cultura da sala de aula, da escola, das escolas em geral. (ERICKSON, 1992).

O etnográfo, utilizando uma teoria crítica de análise aliada à abordagem etnográfica, procura identificar o significado nas relações sociais de classe, etnia, linguagem, gênero, e a cena imediata onde estas relações se manifestam. Por exemplo: numa entrevista de seleção para um trabalho podemos investigar as formas de mobilidade social aplicadas nesse local de trabalho. A microanálise etnográfica leva em consideração não somente a comunicação ou interação imediata da cena, como também a relação entre esta interação e o contexto social maior, a sociedade onde este contexto se insere.

A etnografia, em geral, serve de "background" para a microetnografia. No estudo de caso realizado por Shultz; et.al. (1979) foi analisado o turno de fala, e os padrões culturais da fala, comparando culturalmente um grupo familiar de origem italiana com uma família americana. Neste caso após extensivo trabalho de observação participante, alguns segmentos de fala foram destacados para microanálise. Exemplo disso está em um outro trabalho etnográfico (MATTOS, 1992) baseado nas percepções sobre o fracasso escolar entre três grupos: 1 ) jovens multirepentes e excluídos; 2) pais, professores e diretores de escola; 3) políticos e administradores do sistema educacional. A pesquisadora realizou um estudo microanalítico de uma sala de aula para ilustrar como as relações intra-escolares, especialmente a relação professor-aluno, destacando como podem contribuir para o entendimento sobre os processos de exclusão escolar nas séries iniciais do Ensino Fundamental. 
Na microanálise etnográfica, quando estudamos a sala de aula, observamos por um longo período de tempo, uma escola, uma sala de aula, um professor. Para depois particularizaremos um processo interacional ou um fato que consideramos microanaliticamente relevante. Isto é, destacamos um fato que numa micro-dimensão pode representar o todo do processo estudado. No estudo de Shultz et. al., (1979), cinco pesquisadores observaram por dois anos, um professor e 27 alunos, visitando as famílias, gravando as aulas, observando as situação da escola, a comunidade local, a situação da comunidade no contexto geográfico e político, a situação cultural do grupo e as relações entre esta comunidade ou esse grupo em contraste ou semelhança com outras comunidades ou outros grupos, observando os detalhes nas formas de fala. Do mesmo modo Mattos (1992), em seu trabalho de pesquisa, observou durante dois anos duas comunidades, uma na favela e outra na zona rural, visitas sistemáticas foram realizadas em classes com dificuldades de aprendizagem. Duas destas classes foram selecionadas para um estudo mais detalhado de oito meses, o que culminou com um estudo de caso de uma delas, descrito através de uma microanálise, onde detalhes da interação entre professora e alunos tornaram-se parte significativa do contexto da sala de aula e do tipo de interação existente. Após este intensivo trabalho de observação, o desafio do etnógrafo é tentar organizar todos os dados como num quebra-cabeça. Partindo do contexto maior olhando a comunidade como um todo até poder destacar uma particularidade de possível generalização ou que melhor ilustra o contexto estudado de modo que possa ser microanaliticamente relevante.

\section{Significado e sua significação}

O significado local e a organização do significado local para a pessoa estudada constituem, assim como a comparação e a descrição densa, aspectos importantes a serem observados no trabalho etnográfico. Pressupomos que no "pequeno mundo" de uma sala de pré-escolar exista uma ordem particular de organização sociocultural, por ser conduzida por um tipo particular de professor, sua filosofia de trabalho, sua origem 
sociocultural, a classe social em que a comunidade está inserida, e ainda por causa da personalidade individual das pessoas envolvidas. Quando existe um grupo de pessoas reunidas para se socializar, uma ordem social é desenvolvida para aquele grupo particular de indivíduos (HYMES, 1977; GOFFMAN, 1981). Isto acontece nas escolas, nas fábricas, nos hospitais, nos escritórios, onde quer que as pessoas se encontrem regularmente para socializar de alguma forma. Existe uma ética de organização e um significado que é peculiar a este grupo especificamente.

A etnografia está interessada no significado local para estas pessoas em particular. Existe este interesse geral em comparação com todos os outros modos de ser e fazer que nós conhecemos como humanos, mas existe também o interesse no estudo de caso local, de ser bem específico sobre o significado da organização de um grupo particular de pessoas. Como na linguística, estamos interessados em alguma coisa que é universal sobre a linguagem enquanto ela mesma, na forma que a conhecemos, mas só podemos aprender sobre a universalidade estudando os casos particulares. Só entendemos a variação gramatical ou fonética das várias línguas, olhando uma língua de cada vez. Em cada língua em particular nós estamos vendo um universo particular, um universal concreto (ERICKSON, 1986). Todo indivíduo fala sua própria língua e dialeto particular; então existe sempre uma forma de falar que é particular a um indivíduo e neste aspecto ele é um universo concreto de estudo da língua.

O interesse no local e no particular está inerentemente conectado com o interesse no geral e universal. Por exemplo, existe alguma coisa sobre o desenvolvimento das crianças que Piaget aprendeu estudando os seus três filhos, que são comuns a todas as crianças, mas precisamos de muito tempo e estudos para nós descobrirmos que nem todas as crianças desenvolvem-se exatamente como as três crianças de Piaget. Então alguma coisa sobre estas três crianças era universal concreto em desenvolvimento, mas outras coisas eram muito específicas a este tipo de crianças oriundas da classe alta, filhas de um intelectual suíço num momento histórico particular. 


\section{Abrangência da Etnografia e suas finalidades}

Os estudos sociolinguísticos preocupam-se com as variações linguísticas e procuraram dentro de uma dada sociedade ou comunidade, por todos os tipos de variações nos modos de falar ou uso da fala (HYMES, 1977). Isto é, quando uma pessoa usa a língua para ser cortês, para persuadir, não iremos procurar um tipo de persuasão ou um tipo de tratamento cortês, queremos observar todos os tipos de tratamento existentes. Todos os modos de humor que uma pessoa manifesta numa dada situação de interação, como também todos os tipos de agrupamentos ou todas as relações de subordinação e insubordinação manifestas em um evento particular ou em uma dada ação neste evento. Queremos saber se numa sala de aula a relação de subordinação e insubordinação entre a professora e os alunos é a mesma para todos os alunos ou se existem alguns alunos que desfrutam de privilégios mais que outros em sua relação com a professora. Entre os alunos, pesquisamos, se é diferente o caráter da relação de subordinação e insubordinação entre eles, se existem variações entre o caso de uma sala de aula específica comparando-se com outras salas de aulas. Queremos investigar as relações entre ricos e pobres, oprimidos e opressores, grandes e pequenos, meninas e meninos, procuramos investigar se diferença em subordinação ou de poder é uma preocupação específica de um grupo em particular. Queremos observar todas as identidades sociais existentes: gênero, idade, classe social, riqueza, entre outras.

A questão básica na pesquisa etnográfica é delinear a abrangência das variações: Qual é a abrangência das variações de "X" ou de "Y”? Se estivermos analisando a família, vamos querer saber quantos irmãos menores existem, não que o nosso interesse esteja somente no tipo de agrupamento por faixa etária, mas também se um dos irmãos menores tem mais privilégios que o outro, se tem, porquê e como este dado é percebido na abrangência geral da organização familiar como um todo. Se estivermos analisando a sala se aula de leitura, quantos tipos de reações a uma aula de leitura têm uma professora? Ela reage do mesmo modo para um tipo de leitura de um 
aluno que para outro tipo? Alguns erros contam para ela mais que os outros? Em que circunstâncias isto ocorre? Quando um mesmo erro é relevante numa interação e irrelevante em outra? São os alunos diferentes quando esta discrepância de reação ocorre? São eles pobres ou ricos, meninas ou meninos, fracos ou fortes? Eles pertencem a uma mesma classe social? Estamos sempre procurando a totalidade de variações manifestas numa ação, fato, fenômeno, ou situação na qual estamos interessados.

\section{Perspectiva dialética}

A perspectiva dialética, assim como a comparação, a densidade descritiva, o significado e sua organização e as variações, consiste numa preocupação da etnografia. Dialética no sentido fundamental da noção, que os norte-americanos chamam, de relação ecológica entre os vários atores sociais ou grupos numa comunidade ou instituição, movimento histórico vivenciado pelos atores sociais num determinado espaço de tempo. Procuramos as relações entre estes fenômenos e não apenas um fenômeno particular. Queremos observar o significado de um erro específico de leitura para uma criança, comparandose este erro com o de outra criança na mesma situação de leitura, querendo saber se existem privilégios entre as duas. Queremos saber como agem as meninas em relação aos meninos. São os modos de agir delas iguais ou diferentes aos dos meninos? Não estudamos somente as meninas ou os meninos, estudamos também as relações entre eles. Nós não estudamos a escrita isoladamente, nós queremos entender como a habilidade em escrever um ensaio literário desenvolvido por uma certa pessoa, pode influenciar a habilidade que esta mesma pessoa pode desenvolver escrevendo um ensaio científico, ou como estas habilidades relacionam-se entre si e em relação às habilidades de outras pessoas nestas mesmas tarefas. 


\section{Quantitativo versus Qualitativo}

Um trabalho quantitativo em educação assim como em outros campos de estudo, muitas vezes, considera o fenômeno isolado em si mesmo e isto pode torna-se problemático; o problema é o uso da quantificação, de um sumário numérico para expressar um fenômeno em sua totalidade, tratando-o de maneira abstrata.

Gostaríamos de tentar entender algumas questões quanto a esta abordagem. Existe uma sofisticada matemática que pode ajudar quanto a isso. No entanto, é a ação operacional de pinçar um item isolado do fenômeno ou contexto e tratá-lo isoladamente da sua totalidade, das relações maiores que este contexto apresenta que se apresenta como um complicador desta abordagem. Tratar o fenômeno diferente do contexto maior a que ele pertence, sem olha-lo ecológica ou dialeticamente, sem olhar o todo e as partes ao mesmo tempo pode fazer com que se perca 0 sentido do todo do fenômeno a ser compreendido.

Nesta abordagem, frequências são tabuladas e comparadas com outro grupo que frequências pinçadas de um outro contexto e podemos perder o sentido de relação entre estes dados ou itens que pinçamos. Este não é um privilégio somente da estatística, mas sim uma questão de utilização de um dado fora de contexto; nós podemos fazer isto sem estatística.

A maioria das falsas argumentações entre quantificação e pesquisa qualitativa está relacionada ao mapeamento das questões fundamentais a que nos propomos a entender, estudar ou pesquisar. Para alguns tipos de pesquisa temos que ter uma percepção dialética ou ecológica, não podemos usar certos tipos de quantificações. De forma isolada. Não que contar as coisas seja um erro, mas porque inerentemente ao ato de quantificar, temos que abstrair um item para contá-lo e as pessoas que fazem quantificação podem estar equivocadas em enfatizarem fenômenos considerados destacados em relação a outros fenômenos.

Não precisamos somente quantificar para intelectualmente fazer ciência. Ocasionalmente crucificamos, por algumas razões, pesquisas estatísticas em educação ou em outros campos, 
as linhas de trabalho do gênero experimental ou estatística, não podemos penalizar a estatística ou as experimentações ou achar que somente estas linhas de trabalho são responsáveis por alguns tipos de problemas nas pesquisas sociais, porque esta não é a realidade.

É importante relembrar que o interesse da etnografia reside no estudo das variações de determinado caso e das relações entre estas variações e as variações próprias do contexto maior em que este caso está inserido. Temos também uma preocupação específica com uma perspectiva dialética ou ecológica na pesquisa social que se contrapõe à abordagem quantitativa no sentido do tratamento que esta linha dá ao caso estudado. $\mathrm{Na}$ abordagem dialética temos interesse na totalidade do problema e não simplesmente no tratamento isolado de uma parte do mesmo. Entretanto, isto não significa que abandonemos a estatística como método de tratamento de dados; ao contrário a quantificação utilizada de maneira sensível será de grande valia para a análise etnográfica.

\section{Interação - Contexto - Interação}

Antes de trabalharmos a utilidade desses conceitos na prática da pesquisa etnográfica, se faz necessário explicar a natureza dos termos que estamos aplicando. Interação é o processo que ocorre quando pessoas agem em relação recíproca, em um contexto social. Este conceito implica numa distinção entre ação e comportamento. Comportamento inclui tudo que o indivíduo faz. Ação é um comportamento intencional baseado na ideia de como outras pessoas o interpretarão e a ele reagirão. Na interação social, percebemos outras pessoas e situações sociais e, baseando-nos nelas, elaboramos ideias sobre o que é esperado, e os valores, crenças e atitudes que a ela se aplicam. Nessa base, resolvemos agir de maneira que terão os significados que queremos transmitir (MEAD, 1938; SCHÜTZ, 1932; WEBER, 1921; WOODS, 1992).

Ao pesquisarmos a organização dos processos de interação é interessante estudarmos como as pessoas em interação formam ambiente um para o outro (KENDON, 1977), até mesmo 
além do limite desta interação imediata, onde sempre existe o interesse nas relações ambientais. Por exemplo, o que significa para as meninas conviverem com meninos em sala de aula? Como as diferenças sócio-culturais-econômicas se manifestam na sala de aula? O que isso significa? Como isto acontece? Como o modo de agir de um grupo ou uma pessoa influencia outro grupo ou outra pessoa? Essas são algumas das questões que estamos interessados quando na investigação sobre a interação na sala de aula.

Concordamos com Geertz, quando explica que o conceito de cultura é semiótico, como tal, não é um poder, alguma coisa que pode ser atribuída casualmente - aos fatos sociais, aos comportamentos, as instituições ou aos processos, cultura é contexto, onde esses fatos, comportamentos, instituições, etc., podem ser descritos de forma inteligível, com densidade (GEERTZ, 1989). Considerar cultura como contexto, implica em ampliar nosso entendimento sobre contexto, como simplesmente um local, o background de uma cena, aquilo que é parte integrante do fato, do evento, significa estudar também o que entendemos por cultura. Cultura é forma como o homem significa o seu mundo a partir da teia de signos e símbolos que ele criou e teceu ao longo de sua história (WEBER, 1921; GEERTZ, 1989; ERICKSON, 1987).

$\mathrm{Na}$ abordagem dialética da análise de um contexto devemos evitar o estudo de um fragmento da fala isolado, destacado do que esta significa para pessoa que falou e para as outras pessoas dentro do contexto. Devemos observar em detalhe a ação verbal e não-verbal na cena em que ocorre a interação e o evento de fala (KENDON, 1977). A preocupação é com a totalidade. Como a totalidade influência às partes desta totalidade em si mesma e em cada outra parte do todo.

Interação é movimento, porque existe uma nova atividade acontecendo a cada momento, existe um novo momento da história ocorrendo a cada movimento social cotidiano. O contexto existe e isso é importante de ser determinado, mas é importante ainda saber a recorrência deste contexto em relação ao objeto de estudo. Saber quando um contexto aparecerá novamente, seu padrão de recorrência, é parte fundamental da 
aprendizagem da análise sociocultural. A questão que envolve a identificação de um contexto já foi explorada em alguns estudos interpretativos e envolve um tipo característico de problema apresentado em pesquisas etnográficas - como uma pessoa pode usar apropriadamente uma forma de interação social que se torna imprópria em outro contexto. Esta impossibilidade de contextualizar um dado de pesquisa dificulta para o pesquisador entender o significado da interação para o seu estudo (SHULTZ; et.al.,1983). Estamos nos reportando ao entendimento da ecologia ou dialética de organização de uma cena interativa, como a interação muda de momento para momento, de contexto para contexto é vista como um sistema flutuante, não fixo, portanto, difícil de significar.

\section{A ironia da abordagem etnográfica}

A ironia neste projeto intelectual que é a etnografia é que o que o etnógrafo tenta fazer continuamente é falar sobre organização da interação no contexto de modo que esta fala seja significativa para os atores sociais que estamos investigando. Como nos diria Paulo Freire, falar com ele e não sobre eles, e isso é uma tarefa muito difícil, se não, quase impossível.

$\mathrm{Na}$ tentativa de significar o local pela narrativa descritiva usando termos que são o mais próximos possíveis daqueles usados pelos atores sociais que participam deste projeto, termos que eles usariam se lhes fossem permitido falar. Fazer isso é diferente de escrever "protocolos" de fala onde se desenvolve uma interação com grande detalhe do comportamento do que as pessoas fazem. Estes podem ser acurados, mas o que os torna etnográficos são as descrições feitas usando os termos mais próximos dos problemas e significados numa perspectiva das pessoas mesmas. Ao escrevermos uma narrativa, temos que colocar os atores como eles se apresentam sob a perspectiva deles. Para isso é importante se conhecer o significado local da ação. Ao tentarmos escrever sobre o outro, o ethnoe, de uma maneira em que o ponto de vista dele seja considerado, estamos tocando num ponto frágil da utilização da abordagem etnográfica: a tentativa de fazer sentido, das maneiras de organização 
dos outros de um modo que não seja comprometedor, não seja invasor, não seja discriminatório, não seja opressor, ou não seja excludente.

A irônica dificuldade deste trabalho é que, a priori, nunca conseguiremos dar conta desta tarefa - descrever o outro sob o ponto de vista dele mesmo. Na melhor das intenções, utilizando instrumentos como o vídeo, podemos chegar mais perto da ação que está realmente acontecendo, mas isso não é suficiente. Portanto, genericamente é frustrante e insatisfatório o trabalho de pesquisa etnográfica. Essa ironia deve motivar a meditação para os pesquisadores, mas é o reconhecimento deste dilema que nos impulsiona na tentativa de sua superação. O reconhecimento desta limitação não deve porém nos imobilizar ou criticar radicalmente. Este tipo de abordagem, ao contrário, reconhece os pontos frágeis de um paradigma científico de investigação indicando quando podemos melhor utilizá-la em nossas pesquisas.

\section{Ênfase na questão de pesquisa}

O trabalho etnográfico tem mais interesse na proposta da pesquisa do que no procedimento de coleta de dados. Um instrumento de pesquisa não constitui necessariamente um método de pesquisa. Portanto, devemos enfatizar os problemas de conteúdo da pesquisa, do tema a que nos propomos pesquisar, tanto quanto ou mais que, nos procedimento utilizado por ela. Em etnografia o trabalho de investigação precisa ser visualizado em sua totalidade, com propósitos bem definidos.

A concepção teórica que define um fenômeno primário de interesse no estudo etnográfico sobre o processo de ensinar, por exemplo, é muito diferente dos interesses que orientavam os estudos sobre este processo tradicionalmente. Não queremos com isso fomentar a competição entre os diversos paradigmas que orientam a pesquisa educacional historicamente, ao contrário a convivência harmônica de todos os modos de fazer pesquisa, algumas vezes até a superposição 
de modelos, demonstra que a esta convivência é necessária e, até desejável. Os velhos paradigmas não morrem, na melhor das hipóteses, podem ser superados pelos novos, incorporando-os.

Em etnografia tentaremos combinar uma análise detalhada de comportamentos, seus significados no dia-a-dia de interação social. Analisaremos também o contexto social maior em que este comportamento está inserido. A análise da interação face a face é uma das formas de procedimento que podemos escolher para realizar esta tarefa. Queremos ser específicos sem sermos abstratos, sermos empíricos sem sermos positivistas, sermos rigorosos, sem sermos obsessivos (ERICKSON, 1988).

\section{O trabalho etnográfico}

Sem a pretensão de estar especificando procedimento de investigação etnográfica, mas consciente de que a prática envolve muito fazeres dos quais pesquisados mais inexperientes não estão muito atentos.

O trabalho de campo envolve métodos e procedimentos nos quais temos que ser radicalmente indutivos para a seleção do que deve ser importante para a pesquisa. As categorias ou temas que escolhemos para observar não são necessariamente escolhidos previamente; na maioria das vezes esta escolha se dá a partir do desenvolvimento do trabalho de campo, a esse movimento da pesquisa chamamos hipóteses progressivas (HAMMERSLEY, 1983), pois a cada momento de reflexividade sobre o trabalho de desempenho no trabalho, modifica-se o caminhar e cria-se um movimento próprio aos dados e como de eles refletem as nossas questões. Indução e dedução estão constantemente em diálogo com este procedimento analítico. $\mathrm{O}$ pesquisador delineia sua linha de questionamento os temas que passam a pertencer ao corpo do trabalho. Estes temas podem mudar em resposta ao caráter distinto de um evento ocorrido no local da pesquisa. Por isso, quando realizamos um trabalho etnográfico temos que ter em mente as seguintes questões: 1) o que está acontecendo, especificamente, numa 
ação social que ocorre num lugar ou situação particular?; 2) o que estas ações significam para os atores envolvidos nelas, no momento em que estas ações aconteceram?; 3) como os acontecimentos são organizados dentro dos padrões sociais de organização e dos princípios culturais aprendidos para a conduta no dia-a-dia?; 4) são as pessoas envolvidas no local onde a ação ocorreu consistentemente presentes uns para os outros constituindo ambiente significativo um para o outro?; 5) como o que está acontecendo num lugar, sala de aula (como um todo) se relaciona com acontecimentos ocorridos em outros níveis do sistema, fora ou dentro deste local (escola, família da criança, o sistema escolar, federal, estadual)? e, 6) como as ações rotineiras da vida num local determinado é organizado comparado com outras ações ou modos de organização social de vida numa abrangência maior de lugares no tempo e no espaço?.

$\mathrm{Na}$ pesquisa educacional, respostas para perguntas como estas devem ser consideradas pela seguintes razões: 1) a invisibilidade da rotina diária (“tornar” o que nos é familiar, estranho); 2) a necessidade de entender e documentar detalhadamente a prática social concreta dos atores; 3) a necessidade de estudar o significado local dos acontecimentos para os atores; 4) a necessidade de um entendimento comparativo de diferentes locais onde ocorrem ações sociais e, 5) a necessidade do entendimento comparativo que vai além da compreensão imediata das circunstâncias locais da ação.

\section{Considerações finais}

Na pesquisa etnográfica a especificidade das ações, as perspectivas e significado dos atores sociais são consideradas. $\mathrm{O}$ grupo de maior incidência de interesse como participantes nesta abordagem de pesquisa, são como já consideramos, pessoas diferentes, portanto, passíveis de serem desprezadas em outras abordagens de pesquisa por não constituírem um padrão determinado e validável para generalizações para o todo da sociedade. Possuidores de reduzido poder de participação como membros ativos de uma sociedade - meninos de rua, presidiários, negros, mulheres, professores, estudantes, trabalhadores, 
pacientes de hospitais e hospícios - perfilam entre os participantes mais comuns em pesquisas etnográficas.

Os significados e as perspectivas que buscamos em etnografia, são, muitas vezes, inconscientes para as pessoas que os possuem. Estas são, às vezes, pouco articuladas para explicitar concretamente sua compreensão sobre como vivem e porque agem desta ou daquela forma. A significação dada a sua rotina por esses atores sociais são vistos, algumas vezes, pelo pesquisador, como secundários ao objetivo central da pesquisa, ou irrelevante, teoricamente. Por exemplo, em organizações governamentais as quais os municípios são de certo modo subordinados, expressões como nós já sabemos o que os municípios querem podem ser comumente ouvidas, mesmos que as pessoas dos municípios em questão, sequer tenham sido ouvidas.

Em etnografia de sala de aula, nota-se que é uma exceção, a influência positiva do professor para o sucesso das crianças em risco de fracasso escolar (MATTOS, 1992). O risco do fracasso parece referir-se sempre ao ambiente social ou ao passado familiar da criança. Este risco não se refere à habilidade intuitiva da criança. Sob a perspectiva etnográfica não faz sentido falar sobre esta habilidade intrínseca, de modo isolado, uma vez que a criança sempre se encontra num ambiente social, assim como o desempenho dessa criança. Podemos dizer que o perfil das habilidades da criança a que o pesquisador tem acesso é construído socialmente tanto pelo pesquisador quanto pela criança.

Talvez a mais básica diferença entre a linha etnográfica de pesquisas e as outras pesquisas qualitativas de sala de aula é que estas procuram pela natureza causal do fenômeno, ao passo que a etnografia busca a natureza processual, as formas como as relações são construídas numa sala de aula em particular ou nas interações interpessoais desenvolvidas no âmbito escolar e social. 


\section{Nota}

Para melhor exemplificar os procedimentos que envolvem o trabalho etnográfico, apresentamos em anexo tarefas que foram adaptadas do trabalho de Erickson (1988). Estas tarefas ao serem realizadas possibilitam uma imersão da pessoa que as realiza no trabalho de investigação dentro da abordagem etnográfica e algumas das etapas pertencentes a ele. Esperamos que estes exemplos de exercícios etnográficos venham ajudar, particularmente, alunos e professores que estudam os modos de investigação e seu fazeres. 


\section{Referências}

BLUMER, H. Symbolic Interacionism: perspective and method. Chicago: University of Chicago Press, 1937.

BURNS, A. F. Doing the ethnography of schooling: educational anthropology in action. Anthropology \& Education Quarterly, v. 14, p. 288-291, 1983.

ERICKSON, F.; SHULTZ, J. When is a context? Some issue ans methods in the analysis of social competence. In: GREEN, J. L.; VALLAT, C. (org.). Ethnography and languague. Norwood, NJ: Ablex Press. 1981.

ERICKSON, F. Money tree, lasagna bush, salt and pepper: social construction of topical cohesion in a conversation among italianamericans. In: TANNEN, D. Analyzing discourse: text and talk. Washington, DC: Georgetown University Press, 1982.

ERICKSON, F. Qualitative methods in research on teaching. In: WITTRICK, M. C.(org.). Handbook of research on teaching. New York: Macmillan, 1986.

. Conceptions of school culture: an overview. Educational Administration Quarterly, v. 23, nº. 4, Nov. p.11-24, 1987.

. Ethnographic decription. In: AMMON, U., DITTMAR, N.; MATHIER, K. (ed.) An international handbook of the science of language and society. v. 2. New York: Walter de Gruyter, 1988. p. 1081-1095.

. Ethnographic microanalysis of interaction. LECOMPTE, M. D., MILLROY, W. L.; PREISSLE, J. (Ed.). The Handbook of Qualitative Research in Education. New York: Academic Press, 1992. p. 201-226.

ERICKSON, F.; MOHATT, G. Cultural organization of participation structures in two classrooms of indian students. In: SPINDLER, G. (org.). Doing the ethnography of schooling. New York: Holt, Rinehart \&Winston, 1982. 
ERICKSON, F. What makes school ethnography 'ethnographic'? Anthropology Educational Quarterly, v.15, p. 51-66, 1984.

GEERTZ, C. A interpretação das culturas. LTC: Rio de Janeiro, 1989.

GIDDENS, A. Política, Sociologia e Teoria Social. São Paulo: UNESP, 1997.

GOFFMAN, E. Forms of talk. Philadelphia: University of Pennsylvania Press, 1982.

MATTOS, C. L G. Picturing school failure: a study of diversity in explanations of educational difficulties of difficulties among rural and urban youth in Brazil. 1992. 268f. Thesis. (Ph. D. in Education) - Graduate School of Education, The University of Pennsylvania, Philadelphia. USA, 1992.

HAMMERSLEY, M.; ATKINSOM, P. Ethnography: principles in practice. London: Tavistock, 1983.

HYMES, D. Qualitative/Quantitative research methodologies: a linguistic perspective. Anthropology \& Education Quarterly, v. 8, p. 165-176, 1977.

KENDON, A. Studies in behavior of social interaction. Bloomington: University of Indiana Press, 1977.

LÉVI-STRAUSS, C. Tristes trópicos. Barcelona: Paidós, 1988.

LUTZ, E. W. Ethnography: the holistic approach to understanding schooling. In: GREEN, J. D.; WALLET, C. (Ed.). Ethnography and language in educational setting. Norwood, NW: ABLEX, 1981.

MEAD, G. H. The Philosophy of the act. Chicago: University of Chicago Press, 1938.

MEHAN, H. Understanding inequality in schools: the contribution of interpretative studies. Sociology of Education, v. 62, $\mathrm{n}^{\mathrm{o}} 1$, p. 265-286, 1992. 
OGBU, J. U. School ethnography: a multilevel approach.

Anthopology and Education Quarterly, vol. 12, n. 1, p. 3-29, 1981.

PARK, R. E.; BURGESS, E. W. Introduction to the Sciences of Sociology. Chicago: University of Chicago Press, 1921.

SCHÜTZ, A.; et. ali. Collected papers 1. The problem of social reality (Phaenomenologica). The Hague: Martinus Nijhoff, 1962.

SCHÜTZ, A. The Phenomenology of the social world. Londres: Heinemann, 1979.

SHULTZ, J.; FLORIO, S.; ERICKSON, F. Where's the floor? In: GILMORE, P.; GLATTHORN, A. A. Etnography and Education: children in and out of school. Washington: CAL Press, 1979.

THOMAS, W. I.; ZNANIECKI, F. The polish peasant in europe and America: monograph of an immigrant group. v. 1. Primarygroup organization. Boston: R. G. Badger, 1918.

WEBER, M. Economy and Society. New York: Bedminster Press, 1921.

WILLIS, P. Learning to labor: working class kids get working class jobs. Farnborough, Eng: Saxon House, 1977.

WOODS, P. Inside schools. Ethnography in educational research. London: Routledge, 1986.

WOODS, P. Symbolic interactionism: theory and method. LECOMPTE, M.D.; GOETZ, J.P. (org.). The handbook of qualitatative research in education. London: Academic Press, 1992. 


\section{Tarefa 1 Tornar o familiar estranho}

Auto-observação sobre sua capacidade de observação.

Você tentará observar as diversas situações com as quais se envolve durante o dia. Sociolingüísticamente o problema é sabermos como nós mudamos estilos e estratégias sem percebermos.

Adquira um conjunto de cartões do tipo abaixo representado -você pode precisar de 50 fichas ou mais ou utilize recursos digitais disponíveis em diferentes gadgets do tipo celulares, Ipods, Ipads ou similares
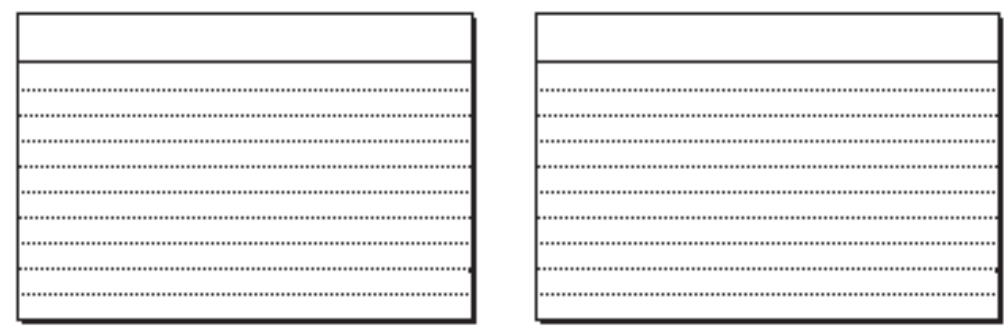

Nestas fichas escreva comentários sobre todos os momento em que você tiver a sensação de ter mudado de cena durante 0 dia - situação de interação com pessoas, animais, objetos, etc.

Pense que você está sendo filmado e lembre-se como uma outra pessoa registraria este evento do seu dia a dia.

Registre nas fichas todas as vezes que a cena mudar. Escreva o mais detalhadamente possível a cena, o lugar e tudo que lembrar. A seguir registre qual foi o sentimento que envolveu a cena, tente ser objetivo, claro e sensível ao contexto em que ocorreu a cena. 


\section{Tarefa 2 Evidenciando diferenças}

Entrevista etnográfica - primeiros passos

Escolha uma pessoa que você considere diferente de você, partindo do princípio de que todos somos diferentes. Escolha aquela que se opõe a você no discurso, no comportamento, nos valores, dentre outras, de modo a estabelecer algum parâmetro comparativo entre você e esta pessoa. Está pessoa será seu entrevistado.

Eleja um tema que possa ser de interesse mútuo e declare seu objetivo para o seu entrevistado ao mesmo tempo buscando em você um alinhamento lógico para conduzir a entrevista, de modo que o tema coberto durante a condução das perguntas da entrevista.

Num processo de perguntas aberta você tentará saber o que o entrevistado pensa sobre o cotidiano dela ou dele, como é esta rotina e o que os eventos desta rotina significam para ele ou ela.

Pergunte: O que você faz ao acordar? Onde costuma ir ? Quando retorna de suas saídas diárias? Se, ele/ela, sente-se confortável com esta rotina? O que acontece para que sinta-se desconfortável ou confortável com o seu dia a dia.

Para investigar sobre a natureza do cotidiano do entrevistado e tentar significa-lo, faça as perguntas de modo a evitar que o entrevistado se exponha de modo embaraçoso. Pergunte a você mesmo como se sente com estas perguntas.

Peça que ao entrevista que fale em poucas palavras, por exemplo: Como você sabe que está interessado em alguma coisa? Como você demonstra que concorda ou discorda de um assunto? Como um colega seu faria isto? Em seu trabalho, escola, família, bairro, reuniões que frequenta, o que as pessoas fazem para demonstrar que o que estão falando naquele momento é o mais importante sobre o que elas tem a dizer ? Para mostrar que estão concluindo o que estão falando. Para demonstrar que você pode confiar nele e que você pode acreditar no que elas estão falando. Como você faz para causar uma 
boa impressão nos outros? Como você demonstra atenção e educação no trato com os outros?

Como observador e entrevistador, pergunte a você mesmo todas as questões de modo a antecipar algumas reações. Se você sentiu-se confortável com as perguntas vá em frente, pergunte!

Observe as expressões do entrevistado, o que faz com o corpo, com os olhos. Se possível utilize o registro de vídeo direcionando a câmera para o entrevistado, além do registro em áudio. 


\section{Tarefa 3 Qual é o ponto específico da análise?}

O processo de análise de dados

Revise suas notas de campo, registros, documentos coletados e outros, identificando um padrão em seus dados.

Formule uma afirmação baseada no padrão que você encontrou.

Retorne aos dados e identifique um evento típico que ilustre a afirmação que você fez. Esta instância - citação, caso, fato, ocorrência , vai prover evidências de que o que você está afirmando está realmente acontecendo, pelo menos uma vez, e de preferência será uma cena ou fato cuja frequência ocorra com regularidade num determinado evento.

Escreva sua afirmativa em forma de vinheta narrativa - que não deve ser maior que duas páginas e meia. Nesta vinheta apresente algumas sentenças para identificar o local onde o evento se deu, seja o mais concreto, vivido e preciso que você puder quando descrever a sequência do evento. Apresente detalhes específicos de comportamentos verbais e não-verbais, citações diretas de fala, e descreva o local físico. Dentre diferentes unidades que compõem a ação na sequência como um todo, varie o nível descritivo de detalhes. Use variações - nos detalhes que deixou de fora, e especialmente nos detalhes que você incluiu para chamar a atenção e deixar claro para o leitor que o evento que você descreveu é consistente e valida a afirmação que você fez. No final da vinheta, reitere a sua afirmação e complementea com alguns comentários interpretativos, contando ao leitor o ponto chave da vinheta. Complemente, se possível, com teorias e outros casos analisados em outras pesquisas.

Agora faça outra afirmação sobre o mesmo evento que você descreveu na primeira vinheta. Esta deve ser também uma afirmação sobre outro padrão recorrente encontrado em seus dados. No entanto, a segunda afirmação deve ser diferente da primeira - isto é, se sua primeira afirmação foi sobre um padrão de percepção do professor, por exemplo, faça a segunda sobre um padrão de percepção do aluno. 
Escreva sua segunda afirmação. Siga os mesmos passos que seguiu para a primeira vinheta narrativa. Mude o tipo de detalhes que você deixou de fora, e mude o nível de detalhes ao longo de uma unidade constitutiva da ação em toda a sequência dos eventos. De modo que a vinheta reescrita agora, ilustre sua segunda afirmação melhor que ilustra a primeira. Outra vez, siga a vinheta e reitere sua segunda afirmação com pontos substantivos que a ilustrem, adicionando algumas sentenças com comentários interpretativos, incorporando teorias conhecidas ou novas que pretende formular com os seus dados. 


\section{Tarefa 4 Espere até que você ouça isto!}

Os dados da pesquisa falam com você

Revise seus dados de entrevista, de vídeos, de documentos, etc., para identificar um padrão em seus dados diferente daqueles que foram utilizados no exercício anterior.

Faça uma afirmação baseada no padrão que você identificou.

Volte aos seus dados procure pelo que as pessoas falaram no local - tanto dados de entrevistas quanto dados das notas de campo ou outros similares. Escolha uma citação de pelo menos uma sentença - quando de entrevistas, é preferível duas ou três sentenças - que ilustre e garanta sua afirmação.

Escreva sua afirmação. Siga a exata transcrição - se fizer uso de áudio-teipe da citação. Não use paráfrase daquilo que a pessoa falou, deixe com a exata fonologia, palavra escolhida, e gramática que a pessoa usou. Se o tom de voz, o tempo, ou o volume forem importantes e significativos tente mostrar isso na forma que você apresenta a citação. Acompanhe a citação com dois conjuntos de sentenças contendo comentários interpretativos, no qual você explica ao leitor o que você acha que está pessoa disse-qual o significado que as palavras desta pessoa tem para ela, no seu entendimento. No primeiro comentário interpretativo - que não deverá ser mais que um parágrafo, explique o significado da citação com base no formato e no conteúdo da citação mesma (isto é, palavras escolhidas, tom de voz, etc.). No segundo comentário interpretativo - lembre-se, que deve ser o mais breve possível - acrescente quantas informações contextuais achar necessário para a fazer uma triangulação, das informações das notas de campo, que acrescente significado para a citação ou que clarifique seu significado.

Retome os dados, reveja-as, e identifique outro padrão.

Faça uma afirmação baseada no segundo padrão encontrado.

Escreva uma afirmação, citação e comentários interpretativos complementares como descrito anteriormente. 
Quando o etnógrafo realiza este exercício, inúmeras vezes, verifica que os dados coletados transformam-se de um conjunto amorfo de textos, áudios e vídeos em dados significativos reveladores do conteúdo que quer expressar muito perto dos atores investigados. Isto é o dado só é dado quando transforma-se em dado, quando fala com o pesquisado sobre seu significado imediato para o conjunto do fenômeno estudado. 


\section{Tarefa 5 Onde está a ideia nova?}

A inovação científica como um pressuposto da pesquisa

Leia, no mínimo, quatro artigos, capítulos delivros diferentes e um livro inteiro, num campo que você não está familiarizado e em tópicos que você nunca considerou antes. Tente escolher material com alguma conexão com as ligações chaves que estão emergindo nos seu estudo, mas tente fazer disto uma conexão distante, ou pelo menos abstrata. Por exemplo, se questões sobre as relações entre supervisores e supervisionados salientou-se no seu estudo, procure por um artigo num pequeno número de textos em supervisão e moral numa tropa do exército, com o sargento como supervisor e os soldados como supervisados. Ou encontre um artigo sobre as relações de supervisão entre médicos e enfermeiras em um hospital.

Para esta tarefa, evite ler artigos sobre escolas. Você já sabe muito sobre elas e já tem muitas coisas como certas sobre escolas e educação. Encontre qualquer outro assunto (institucional ou local) diferente da escola para ler sobre ele. Porque nós assumimos que você já está consideravelmente familiarizado com o campo de psicologia, você não deve ler artigos ou livros sobre psicologia do conhecimento, psicologia da personalidade, psicologia clínica, ou desenvolvimento infantil. Você pode preferir ler artigos sobre psicologia social sobre pequenos grupos, entretanto, aconselhamos que você leia algum artigo em ciências sociais - antropologia, sociologia, ciência política, história social, e possivelmente economia. Você pode também procurar por artigos de ciências sociais em arquitetura, medicina, legislação, justiça criminal, negócios, governo, estudo de comportamento animal (etologia) e em ecologia de plantas e animais.

Para cada item que você escolheu para ler, apresente uma citação bibliográfica completa e uma breve anotação do conteúdo do item. A anotação deve conter aproximadamente três sentenças sumarizando o ponto mais importante ou os pontos mais importantes da leitura e aproximadamente duas sentenças relatando o que você aprendeu sobre a leitura e que foi relevante para o seu estudo. 


\section{Tarefa 6 Rascunhando o relatório final}

A produção científica

Introdução: descrever o problema da pesquisa, as questões da pesquisa, e o significado do estudo - planeje ser o mais breve possível, você pode sempre expandir este item mais tarde.

Visão geral sobre o local escolhido: descrever sua situação em relação à instituição ou comunidade estudada; atividades maiores durante o ano, a semana, e diariamente; o local físico - mapas, sinopses, tabelas e gráficos são apropriados para esta função, neste momento você pretende dar uma visão por exemplo, de uma distância de $30.000 \mathrm{Km}$. para $5.000 \mathrm{Km}$ ou para uma visão mais ampliada.

Descrição e interpretação: afirmações mais importantes, as ilustrações produzidas através das vinhetas e citações diretas, acompanhadas de material de ligação e interpretação.

Sumário e conclusões: inclua as discussões sobre as interpretações alternativas para os dados, o significado das interpretações encontradas, questões deixadas de lado ou sem respostas, novos questionamentos, futura direção para a pesquisa.

Autobiografia intelectual: comece com a questão que inicialmente era a mais importante, uma discussão de como o seu pensamento mudou, como procurou por des-confirmações das evidências que você investigou, como os caso discrepantes foram considerados, como perspectivas teóricas mais recentes contribuíram para a análise, etc.

Ensinando sobre os resultados: escrever algo específico sobre como você planeja ou como já comunicou os resultados do que foi estudado. Imagine que a sua audiência deve ser a comunidade científica de modo geral e ao mesmo tempo as pessoas simples. Se conseguir fazer com que pessoas simples (não-acadêmicas) entendam os seus resultados você está pronto para qualquer audiência. Entretanto, se estes resultados são apenas dirigidos a uma audiência acadêmica você pode estar falando de maneira abstrata que leva, muitas vezes a reduzir os longos anos de dedicação do seu trabalho a uma prateleira de biblioteca da sua universidade ou a sua própria. 


\title{
Tarefa 7 Quadros sinópticos, tabelas e gráficos
}

Não abuse das tabelas, mas não as deixe de lado.

Conte a frequência - após vários dias de observação, durante o tempo de observação e comparando os vários dias -para determinar padrões nos seus dados.

Faça duas afirmações baseadas nos padrões que você descobriu. Ilustre cada afirmação com um gráfico de barras, tabela de contingência, ou outro tipo de tabela de frequência simples. Apresente estas com pelo menos um parágrafo de discussão explicativa.

Faça dois quadros sinópticos, os quais possam ilustrar padrões ou afirmações de seus dados. Apresente estes acompanhados de uma discussão explicativa - escreva pelo menos um parágrafo.

Nota - Quando você apresenta ao leitor uma tabela de frequência ou quadro, você deve sempre considerar cuidadosamente o conteúdo do título - de modo que a afirmação seja clara no título. Na discussão que acompanha o quadro ou tabela, informe ao leitor em que ele deve prestar uma atenção especial dentro da tabela. Por exemplo:

\begin{abstract}
"notei que durante os últimos três dias eu observei que quando o professor estava terminando a unidade de eletricidade, somente um terço dos muitos comentários irrelevantes feitos pelos alunos apareceram nas notas de campo, comparando com as vezes que este tipo de comentários apareceram nos três primeiros dias em que esta unidade foi ensinada. Isto sugere que ....”.
\end{abstract}

Os quadros, sinópticos, tabelas e gráficos devem, preferencialmente, serem originais e construídos com o fim específico de consubstanciar dados relevantes para significar os resultados da pesquisa. Isto é, dados e tabelas construídos por outrem ou retirados de estatísticas e relatórios não devem ser utilizados. Entretanto, podem ser descritos e informados na referência para comparação e validação dos seus próprios dados. 


\section{Tarefa 8 Como meu pensamento mudou desde o início da pesquisa}

Autobiografia intelectual - mudança no processo.

Escreva um rascunho de um ensaio com o título acima. Este ensaio vai se tornar a seção final do seu relatório. Em não mais de cinco páginas, escreva sobre as questões da pesquisa, orientação teórica, pressupostos baseados em experiência anterior, valores e credos aprendidos e qualquer coisa mais que mudou desde de que você iniciou o estudo como resultado de experiências ou leituras que você fez.

Lembre-se, um bom indicador da qualidade da sua análise é o modo no qual seu pensamento mudou durante o curso da pesquisa. Isto mostra que você estava aberto a novas informações, desconfirmando informações, procurando novas perspectivas teóricas, e não apenas fazendo trabalho de campo para documentar as pressuposições favoritas com as quais você iniciou a pesquisa. Estas suposições podem permanecer até o fim, mas elas devem pelo menos serem vistas sob uma nova luz depois de você realizar o trabalho de campo, tendo lido uma nova literatura, e tendo gasto tempo refletindo sobre seus dados. Além disso, novas pressuposições e questionamentos devem ter emergido. Tudo isso pode ser emocionalmente difícil, seja franco e mencione isto também, em termos específicos sem deixar que essas dificuldades e impasses ocorridos durante o processo de pesquisa se transformem em um muro de lamentações. O leitor do seu texto está interessado no que você encontrou e não no que não conseguiu encontrar no processo, mas no que facilitou a pesquisa e nas eventuais dificuldades.

No seu ensaio, seja o mais específico que você puder sobre como as questões da pesquisa e as pressuposições mudaram e qual foi a experiência ou leitura que o levou a mudar de ideia. 
